\title{
THE B VITAMIN REQUIREMENTS OF THE
}

HOUSE CRICKET

by

Claude Ritchot

A thesis submitted to the Faculty of Graduate Studies and Research in partial fulfilment of the requirements for the degree of Master of Science.

Department of Entomology, McGill University, Montreal. 


\section{ACKNOWLEDGMENTS}

Financial assistance received from the

Agricultural Research Council of the Province of Quebec is gratefully acknowledged.

The author is thankful to Professor J.E.McFarlane for constructive criticism and advice. 
I. INTRODUCTION . . . . . . . . . . . I

II. LITERATURE REVIEW . . . . . . . . . . 2

A. THE STORED FOOD PRODUCTS INSECTS . . . 5

1. COLEOPTERA

a. Lasioderma serricorne and Stegobium paniceum ... . 5

b. Oryzaephilus surinamensis . . 6

c. Tribolium confusum. . . . . 7

d. Tenebrio molitor. . . . . 8

e. Ptinus tectus ....... 9

F. Dermestes vulpinus. . . . . 9

8. Palorus ratzeburgi...... 9

2. LEPIDOPTERA

a. Tineola bisselifella. . . . 10

b. Ephestia elutella ..... . 11

c. Ephestia kuehniella ..... 11

d. Ephestia cautella and Plodia interpunctella .... . 11

B. THE DIPTEROUS LARVAE . . . . . . . II

a. Drosophila melanogaster . . . 12

b. Musca domestica . . . . 12

c. Hylemya antiqua . . . . . 13

d. Aedes aegypt1 . . . . . 13

- Psoudosarcophaga affinis. . . $I_{4}$

f. Phormia regina. . . . . 15 
C. THE COCKROACHES . . . . . . . 15

a. Periplaneta americane. . . 15

b. Blatella germanica . . . . 16

D. THE PHYTOPHAGOUS INSEGTS. . . . . . 17

a. Chilo suppressalis . . . . 17

b. Hylemya antiqua. . . . . . 18

c. Pyrausta nubilalis . . . . 18

d. Pectinophora gossypiella . . 19

๑. Dacus dorsalis . . . . . 19

f. Bombyx mori. . . . . . 20

g. Prodenia eridania. . . . . 20

h. Anthonomus grendis . . . . 20

III. MATERIALS AND METHODS

A. REARING OF THE ADULTS . . . . . . 22

a. For Acheta domesticus. . . . 22

b. For Gryllodes sigillatus . . . 23

B. TESTING OF THE DIETS. . . . . . . 23

C. CRITERIA. ........... 24

D. COMPOSITION OF THE DIETS. . . . . 25

E. PREPARATION OF THE DIETS. . . . . . 26

a. Order of mixing. . . . . . 26

b. The vitamin mixtures ..... 27

IV. RESULTS . . . . . . . . . . . . 29

A. EXPERTMENT I . . . . . . . . . 29

B. EXPERIMENT II . . . . . . . . 30 
$\underline{\text { Page }}$

a. The importance of Iipid in the diet....... . 30

b. The importance $10 \mathrm{~B}$ vitamins to Acheta domesticus. . . . . 31

C. REPIICATE OF EXPERIMENT II . . . . . 33

D. EXPERIMENT III . . . . . . . . . 34

V. DISCUSSION AND CONCLUSIONS. . . . . . . . 34

A. EXPERIMENT I. . . . . . . . . 34

B. EXPERIMENT II AND ITS REPIICATE. • • • 35

1. THE IMPORTANCE OF THE IIPIDS . . - 35

2. THE IMPORTANCE OF TEN B VITAMINS • 37

๑. Inositol. . . . . . . 37

b. p-Aminobenzolc acid . . . - 37

c. The major B vitamins. . . . 38

d. Folic acid. . . . . . . 39

๑. Choline chloride. . . . . 39

f. Biotin........ . . 40

g. Conclusion. . . . . . . 40

C. EXPERIMENT III . . . . . . . . . 41

VI. SUMMARY . . . . . . . . . . . . . 42

VII. BIBLIOGRAPHY. . . . . . . . . . . . 44

VIII. TABLES. . . . . . . . . . . . . 55 


\section{INTRODUCTION}

The house cricket Acheta domesticus (L.) is a very convenient laboratory insect; it is easy to rear (Ghouri and McFarlane 1958), it has a sufficiently short Iffe cycle, the eggs and young nymphs are large enough not to necessitate any special apparatus to be manipulated, and, finally, neither disoases nor parasites are factors influencing the results.

Nevertheless, A. domesticus has not been used very often by research workers, and the first to study seriously some aspects of its nutrition were Ghouri and McFarlane (1958), and McFarlane et al. (1959). The latter described artificial diets which permitted good growth and development of the nymphs. However, their diets were not made entirely of pure chemicals: they all contained vitamin-free casein, as a source of protein, instead of pure amino-acids, and wheat germ oil was used as lipid material. Yeast, on the other hand, could be replaced by an adequate vitamin mixture.

The present work is a continuation of these first steps, and its main purpose has been the determination of the vitamin requirements of this insect. But, in addition, a few tests have been made on the dietary importance of some 
lipid materials, and, finally, growth of the cricket Gryllodes sigillatus (Walk.) on the best artificial diet for A. domesticus will be reported.

What is important in these experiments is that they widen the field of work for the entomologists. The more insects there are that can possibly be worked with in the laboratory, the more information may be obtained. As far as insect physiology is concerned, A. domesticus and Gryllodes sigillatus will now have their place in the Ifterature, which will enable some new problems to be solved.

\section{LITERATURE REVIEW}

A general survey of the vitamin requirements of the different insects investigated up to the present time will be presented in this chapter. The literature on this subject is not very voluminous; this aspect of entomology was first approached seriously only about twenty years ago (Fraenkel and Blewett, 1942), at the time when pure vitamins were making their appearance on the market.

However, few insects have had their vitamin requirements determined. This is mainly due to the fact 
that most of them have habits which make them difficult or as yet impossible to rear under laboratory conditions. Therefore, the information now available has come from insects which do not give rise to special rearing problems. These can live and reproduce in the laboratory without elaborate handling, and accept artificial diets presented to them without needing any special stimuli.

The rirst insects to be adopted for such studies were the stored food products insects, their habitat being easily reproduced in the laboratory. A great advantage in working with these insects is that they grow and develop well on dry diets, in which no microorganisms can develop and transform some nutrients. Moreover, belng small, they do not eat very much food. In addition, once they have been put on the diets, they can remain there for the length of the experiment, obviating the necessity of many manipulations by the worker.

However, some interesting work has also been done with a few phytophagous insects, and some dipterous larvae. The main problem in rearing these insects is that they require a liquid or semi-liquid diet. This means that antiseptic precautions have to be taken to prevent the development of microorganisms, always undesired in nutrition experiments. 
The cockroaches have also been successfully studied. They resemble the stored food products insects in accepting a dry diet, but a water source of some sort has to be avallable (Noland ot al., 1949a). A fow other insects w111 be mentioned in this chapter.

The term vitamin and growth factor are used in the same sense in this paper, the effect of the $B$ vitamins being considered usually in relation to growth only. It is generaliy accepted that the B vitamins are part of co-enzyme systems in organisms, but such a function has not jet been described either for inositol or for choline. Also, the latter two factors are present in the body tissues in concentrations much higher than those of the other vitamins (Furton and Simmonds, 1953). However, for the sake of clarity, and since all the literature on insect nutrition refers to inositol and choline as parts of the B vitamin complex, no distinctions between them and the other vitamins are made in the present work.

A vitamin is said here to be required or essential when very poor growth and Ifttle maturation or none at all are recorded with the nymphs fed a diet lacking it. In many cases however, even if growth is poor, there is still a high percent of maturation. In such instances, the vitamins omitted are said required, but a note is given to explain to what extent they are so. 


\section{A. THE STORED FOOD PRODUCTS INSECTS}

The major part of the Iiterature on insect nutrition is devoted to work on the stored food products insects. To make this review easier to follow, the term 'major B vitamins', which Lipke and Fraenkel (1956) used in a recent publication, will be adopted here in the same sense, representing the vitamins of highest importance for most of insects: thiamine, riboflavin, nicotinic acid, pyridoxine, and pantothenic acid.

\section{COLEOPTERA}

a. Lasioderma serricorne F., and Stegobium paniceum I. When unsterilized, Lasioderma serricorne and Stegobium paniceum were able to grow and develop normally in the absence of most of the B vitamins. Lasioderma had retarded growth only in the absence of thiamine or choline chloride, while stegoblum reacted the same way only in relation to pantothenic acid, but could not grow at all without thiamine (Fraenkel and Blewett, 19/43a). These results were due to the fact that these insects harbored intracellular symbionts which have since been identified as symbiotic yeasts (Fraenkel and Blewett, 1943c; Pant and Fraenkel, 1950). However, when the eggs were sterilized, the results differed and corresponded to those obtained with other insects in general: inositol and p-aminobenzoic 
acid were not required, but no life was possible in the absence of any of the major B vitamins or of choline chloride (Fraenkel and Blewett, 1943b).

b. Oryzaephilus surinamensis $I$.

Fraenkel and Blewett (1943a), when working on the vitamin requirements of various insects, found that Oryzaephilus surinamensis could live in the absence of some vitamins which seemed indispensable for other closely related insects. Only the omission of riboflavin, nicotinic acid or pantothenic acid could stop larval growth. So the normal conclusion was drawn that this situation was probably due to the presence of symbionts. However, Lemonde and Bernard (1953) repeated this work and reported that Oryzaephilus required absolutely all the major $B$ vitamins, with the exception of thiamine. Without biotin or follc acid, the rate of development was slowed down, but the larvae reached the adult stage. Choline, inositol, or p-aminobenzoic acid had no apparent effect. However, a special situation occurred in the case of the following three vitamins: thiamine, inositol, and p-aminobenzoic ac1d. When any one of them was left out of the diet, growth was as good as with the control diet. But when all three were omitted, no development at all was noticed. The authors concluded that there must be a special relation 
between these vitamins. Moreover, the same authors also reported that Oryzaephilus did not do as well on the diet having a vitamin mixture as on the diet where geast was used as a source of vitamins. This showed, according to them, that in yeast there wer $\theta$ one or more other factors favourable to the growth of this insect (Lemonde and Bernard, 1953).

c. Tribolium confusum Duval.

Tribolium confusum has been quite extensively investigated nutritionally, and, as far as vitamin requirements are concerned, it has been shown comparable to sterilized Lasioderma or Stegobium. No growth was possible in the absence of any of the major B vitamins, biotin, or folic acid. Omission of choline retarded growth significantly, but did not stop it (Fraenkel and Blewett, 1943a). Lemonde and Bernard (1955) have stated that this insect seemed to synthesize choline to a certain extent. This explains well the results of Fraenkel and Blewett (1943a). Tribollum has also been reported to require two additional factors which are present in yeast, one being in the water soluble fraction, and one in the water insoluble fraction (Fraenkel, 1949; French, 1954; Offhaus, 1952; Charbonneau and Lemonde, 1960). French and Fraenkel (1954) and other authors (Frobrich, 1953; Mag1s, 1954) studied the relation of the formation 
of normal Tribollum adults to the carnitine content of the larval diet. It seemed most probable that carnitine must be added to the diet if normal maturation was desired. This insect, however, is in no need whatsoever of inositol or p-aminobenzolc acid (Fraenkel and Blewett, 1943a).

d. Tenebrio molitor L.

The yellow mealworm Tenebrio molitor, like Tribolium, does not harbor any symbionts since, for larval growth, most of the $B$ vitamins are required, except choline and, as usual, inositol and p-aminobenzoic acld (Fraenkel, 1950). No growth at all could be observed in the absence of any of the major B vitamins. Without biotin or folle acid, the insects developed very slowly. Choline, even if not important here, still improved very slightly larval growth, which was not the case for inositol or p-aminobenzoic acid. Tenebrio differed from Tribolium in the necessity of its larvae having an appropriate concentration of carnitine in the diet; no growth was obtained otherwise and nearly all the larvae died (Fraenkel and Chang, 1954). For normal adults, higher amounts of carnitine were required: 1.5 micrograms per gram of the diet in comparison to 0.35 micrograms for normal larval growth (Fraenkel and Chang, 1954). 
e. Ptinus tectus Boie

The Coleopteran Ptinus tectus reacted similariy to Tenebrio or Tribolium in the absence of the different B vitamins, with the exception of carnitine. There was practically no growth when any one of the major $B$ vitamins was missing (Fraenkel and Blewett, 1943a). Inositol or p-aminobenzoic acid did not seem to affect the results when either included in or omitted from the diets (Fraenkel and Blewett, 19438).

f. Dermestes vulpinus L.

Fraenkel's work on Dermestes vulpinus (1951) came to about the same conclusions as for the majority of the other insects. Inositol and p-aminobenzoic acld were not required. No growth occurred when there was a lack of folic acid or one of the major B vitamins, except thlamine, in the absence of which development occurred, but at a slow rate, resulting in the formation of small pupae after a long larval period. Blotin and choline were shown to have about the same importance as thiamine (Fraenikel, 1951).

g. Palorus ratzeburgi (Wisman)

Cooper and Fraenkel (1952) established the vitamin requirements of the small-eyed flour beetle, Palorus ratzeburg1. This insect was shown to require all the major B vitamins plus choline and carnitine(or vitamin BT). 
Biotin, follc acid or inositol could be omitted without any apparent effect. However, this insect differed from the majority by its need for choline, which had to be present in optimal amounts, 1.e. about 1000 micrograms per gram of diet. A decrease in growth corresponded either to a higher or lower concentration. As far as carnitine is concerned, it was required not only for larval growth, but also for pupation and emergence of the adults.

\section{LEPIDOPTERA}

a. Tineola bisselliella (Hummel)

The larver of Tineola bisselilella were able to grow sufficiently well in the absence of many $B$ vitamins, without, apparently, the help of any intestinal symbionts (Fraenkel and Blewett, 1945). This was the case when riboflavin, pyridoxine, thiamine, or choline were omitted from the diet; however, when maturation occurred, it was only after a long period of slow development. A few adults could also be obtained in the absence of calcium pantothenate. But nicotinic acid was absolutely indispensable. Inositol and $p$-aminobenzolc acid were of no importance at all (Fraenkel and Blewett, 1945). Blotin and folic acid were not tested, but good growth occurred without them; so, if they have some beneficial effect, it is certainly not a very accentuated one. 
b. Ephestia elutella (Btboner)

Ephestia elutella was shown by Fraenkel and Blowett (1945) to require all the major B vitamins and folic acid. The leck of biotin or choline only slowed down growth, and no effect was found from the addition or omission from the diet of inositol or p-aminobenzoic acid.

c. Ephestia kuehniella Zeller

Ephestia kuehniella differed from E. elutella in that its larvae could do much better in the absence of riboflavin (Fraenkel and Blowett, 1945). Moreover, they seemed not to require any choline. Finally, when p-aminobenzolc acid was omitted from the diet, the larvae seemed to develop better (Fraenkel and Blewett, 1945).

d. Ephestia cautella Walk. and Plodia Interpunctella (Hubner) The vitamin requirements of Ephestia cautella and Plodia interpunctella were studied in part by Fraenkel and Blewett (1945). On the arfificial diet they behaved the same way as E. elutella and E. kuebniella: growth took place, but at a very reduced rate. Plodia was studied in relation to biotin and was found to require it for larval growth.

\section{B. THE DIPTEROUS IARVAE}

Other insects than the stored food products insects have been successfully reared in laboratories on 
artificial and even on chemically defined diets, and have had their vitamin requirements studied. We will first of all discuss the results obtai ned with various dipterous larvae.

a. Drosophila melanogaster Meigen

Drosophila melanogaster is one of the best known laboratory insects. Work on its vitamin requirements has been done by Sang (1956). Inositol did not seem to affect growth at all, but p-aminobenzolc acid appeared to improve 1t. Of the major B vitamins, all were essential; moreover, it was shown that riboflavin, nicotinic acid and pantothenic acid were also necessary for pupation. The absence of biotin seemed not to cause any drastic effect on larval development. Folic acid was found important only for eclosion, but not for pupation, which results do not correspond with those of Hinton (195I) who clained that this vitamin was a stimulant for growth and essential for pupation.

b. Musca domestica L.

House and Barlow (1958) did very interesting work on the nutrition of the house fly, Musca domestica. This insect was not shown to require inositol, p-aminobenzolc acid, or follc acid. All the major B vitamins proved to be essential with the excoption of pyridoxine, in the absence of which no significant effect was observed on the larvae, 
but they died at pupation. No survival also resulted from omission of biotin from the diet. The larvae reacted the same way to the absence of choline as to the absence of pyridoxine: normal larval growth, but no pupation.

c. Hylemya antiqua (Meigen)

A study of the vitamin requirements of the larvae of the onion maggot fly, Hylemya antiqua, was made by Friend and patton (1956). In their chemically defined diet, they did not include either inositol or p-aminobenzoic acid; these two factors were presumed unnecessary, since satisfactory growth was obtained without them. All the major B vitamins, plus blotin, choline and folic acid, were considered by the authors indispensable for normal growth and development of the larvae. Vitamin $B_{12}, C o-A$, and thioctic acid were also tested in that experiment, and, even though not essential, in their absence growth was retarded a little, fewer larvae reached the pupal stage, and the ratio males/females was increased.

\section{d. Aedes aegypti L.}

Singh and Brown (1957) studied the nutrition of the mosquito Aedes aegypti. Their conclusions, as far as larval growth was concerned, were that biotin and the major B vitamins, with the exception of pyridoxine, were indispensable. The omission of choline chloride or 
carnitine, although less effective than the former vitamins, did retard growth significantly. The other B vitamins seemed not to have any influence on the larvae. For pupation however, pyridoxine and folic acid were definitely required while $B_{12}$ had only the effect of hastening 1t. p-Aminobenzolc acid, which has not elsewhere been found to have any utility for insects, was useful here for ecdysis which was delayed otherwise.

Q. Psoudosarcophaga affinis (Fall.)

The importance of eleven B vitamins for Psoudosarcophaga affinis was determined by House (1954). He came to the following conclusion: the vitamins which seemed essential for normal growth and development of the larvae were biotin, choline and the major B vitamins, with the exception of pyridoxine. The omission of the latter and also of folic acid, p-aminobenzoic acid, inositol, or $B_{12}$, did not interfere seriously with growth. The diet with $B_{12}$ appeared a Iittle inferior to that without it. The same situation was observed with p-aminobenzoic acid; moreover, the greatest number of mature larvae and the highest growth index rating were obtained on the diet lacking this vitamin. It should be noted here that, in the absence of riboflavin, choline or biotin, still some larvae could reach the third instar; growth was somewhat erratic in these cases and especially when riboflavin had been omitted. 
f. Phormia reging (Meigen)

As is the general case, nelther inositol nor p-aminobenzolc acid are required by Phormia regina larvae. Practically no growth has been recorded in the absence of any of the major B vitamins, while a lack of folic acid, biotin, or choline resulted in significantly delayed development of the larvae in comparison with the control diet (McGinnis et al., 1956; Brust and Fraenkel, 1955). Blotin and follc acid were shown necessary for the emergence of the flies from the apparently normal pupae (McGinnis et al., 1956). As with Tribolium, there is in yeast one or more unknown factors favourable for larval growth of $\underline{P}$. regina (Brust and Fraenkel, 1955).

\section{THE COCKROACHES}

a. Periplaneta americana (I.)

The american cockroach, Periplaneta americana, was found to have vitamin requirements somewhat different from those of the majority of the other insects (sieburth and McLaren, 1953). For normal nymphal growth, they needed only thiamine, pantothenic acid, nicotinic acid, and follc acid. No difference in the rate of development could be noticed between the control diet and the diets lacking $p$-aminobenzolc acid, pyridoxine, vitamin $K$, or riboflavin. However, in the latter case, a high percent 
mortality was recorded after a period of 90 days (Sieburth and McLaren, 1953). Forgash (1958) reported that under aseptic conditions this insect had a need for inositol. When the latter vitamin was left out of the diet, a significant delaying effect on growth appeared only after a nymphal period of 50 days. Moreover, very few nymphs matured and a very high percent mortality was recorded: $75 \%$ after 250 days in comparison with $13 \%$ for those fed the control diet.

b. Blatella germanica (I.)

The vitamin requirements of the German cockroach, Blatella germanica, differed from those of the American cockroach, and they were also far from being comparable to those of the majority of insects investigated (Noland et al., 1949b). Only three vitamins appeared to be required for nymphal growth: pantothenic acid, nicotinic acid, both of which are of the major B vitamins, and choline. Growth was drastically reduced and no adults were obtained when any one of them was missing from the diet. When the rest of the major B vitamins, pyridoxine, thiamine and riboflavin, were absent, Individual variations in growth rate and maturity were marked, and the average growth rate was much slower than that of the control diet. Inositol, p-aminobenzolc acid, blotin, and folic acid had no effect on the nymphs, which 
developed and matured as normally as on the control diet. It was even shown in some cases, $\theta$. g. when follc acid was missing, that maturity was reached oven sooner (Noland et al., 1949b).

It is useful to say here that no special method to rear the cockroaches completely aseptically has been discovered. We would probably have some different results for some vitamins, since Richards (1958) has said that the xenic cockroach has a rich intestinal flora and intracellular bacteroids.

\section{THE PHYTOPHAGOUS INSECTS}

For reasons already mentioned in this chapter, very few phytophagous insects have been the subject of nutrition experiments. By such insects wo understand those which "customarliy eat only fresh plant material (Friend, 1958)". In the literature, only two of them may be sald to have been reared on an appropriate chemically defined diet (Friend, 1958): these two are the Aslatic rice borer, Chilo suppressalis (Ishil and Urushibara, 1954), and the onion maggot fly, Hylemya antiqua (Friend and Patton, 1956).

a. Chilo suppressalis (Walker)

According to Ishil and Urushibara (1954), the larvae of Chilo suppressalis require for normal growth and development 
the major $B$ vitamins plus biotin, folle acid, and choline. However, in their experiments, growth stopped completely only in the absence of the following vitamins: blotin, thiamine, pyridoxine, folic acid, and pantothenic acid. And they reported that the lack of riboflavin, nicotinic acid, and choline would only slow down the rate of development significantly. No role whatsoever could be given to inositol, p-aminobenzolc acid, or carnitine. However, even In the presence of all ten vitamins just mentioned, the larvae developed inferiorly to those fed a diet with a water extract of yeast in addition. Moreover, the diets tested did not give an optimel emergence; Ishil et al. (1956) have stated that in the rice plant there was one or more factors that affect this stage.

b. Hylemya antiqua (Meigen)

Hylemya antiqua has already boen discussed with the group of dipterous insects. However, it is useful to mention here that this is the only phytophagous insect for which a complete chemically defined diet has boen proposed, on which it can develop from egg to adult (Friend, 1955).

c. Pyrausta nubilalis (Habner)

Much work has been done with the European corn borer, Pyrausta nubilalis (Bock et al., 19149) fed artificlal diets containing mixtures of ten $B$ vitamins, which, 
unfortunately, failed to replace brewer's yeast powder. Moreover, one or more unknown factors, called the "corn leaf factor", which were found to be present in corn leaves, grass juice, and other plant materials, were necessary for normal larval growth and development (Beck, 1953). In their absence, efther there was no emergence, no expanding of the wings, or death soon after emergence (Beck, 1953).

\section{d. Pectinophora gossypiella (Saunders)}

Pectinophora gossypiella was found to require absolutely, for larval growth, the major B vitamins, plus folic acid and biotin (Vanderzant, 1956). The omission of choline from the diet of aseptic larvae stopped growth after the fourth larval instar (Vanderzant, 1956). However, under ordinary conditions, p-aminobenzoic acid, choline, inositol, and $B_{12}$ did not seem indispensable. The addition of cottonleaf meal or dried forage plant juice to the diets did not improve them for larval growth, nor did they make the medium more attractive (Vanderzant, 1956).

\section{- Dacus dorsalis Hendel}

Dacus dorsalis has not yet been studied for the vitamin requirements of its larvae. Hagen (1958), however, reported some results on the adult stage. According to him, the omission from the diets of the following vitamins decreased the fecundity of the adults: thiamine, nicotinic acid, follc acld, and choline. 
f. Bombyx mori (I.)

Some information is avaliable on the silkworm, Bombyx mori. Supplementation of mulberry leaves with vitamin $\mathrm{B}_{12}$ increased the protide content of the larver, but no effect was apparent on the production of silk (Bostricco and Arnaudo, 1955). Vitamins $A$ and $C$ were also found to be present in this insect (Yoshida, 1954; Takahashi, 1955).

g. Prodenia eridania (Cramer)

Very few results have been published on the nutrition of the army worm, Prodenie eridania. An artificial diet has been described for it, and the $B$ vitamin source was brewer's jeast powder plus choline chloride, which is now the only determined growth factor for this insect (Elliot, 1955 ). A feeding stimulus was needed and chlorophyll was shown to be efficient for that purpose (Ell1ot, 1955). For normal pupation, grass juice powder had to be added to the diet (Elliot, 1955). The factor present in it could be follc acid, which Fraenkel and Blewett (1947) used in the case of Ephestia kuehniella to replace the grass julce powder (E1110t, 1955).

\section{h. Anthonomus grandis Boheman}

The boll weevil, Anthonomus grandis was shown by Vanderzant (1959) to require inositol for larval growth and development. Up to the present time, this has been the only 
Instance where inositol was of such importance in insect nutrition. Moreover, A. grandis needed this vitamin in concentrations of the range of the other vitamins: about $7.5 \mathrm{mg}$ per $100 \mathrm{gm}$ of the diet (Vanderzant, 1959).

The above represents what the author belleves to be a complete review of the vitamin requirements of insects. It is clear that from species to species, there is considerable variation, so it is nearly impossible to come to a general conclusion including all cases. However, It seoms generally true that insects do not require p-aminobenzoic acid for larval growth, and, in some cases, omission of it improves growth. Inositol is of importance only for Periplaneta americana (Forgash, 1958) and Anthonomus grandis (Vanderzant, 1959). Choline, biotin, and folic acid differ widely in their effects from one to the other; sometimes they are essential, sometimes their absence causes but a delaying action, and sometimes they do not seem to be required at all. On the other hand, the omission of any of the major $B$ vitamins, when no symbiotic action is present, usually stops growth; but each one of them, except nicotinic acid, in one instance or another, is not essential, some growth and maturation occurring in their absence. 
III. MATERIALS AND METHODS

\section{A. REARING OF THE ADULTS}

a. For Acheta domesticus

The method used to rear the adults was based on the work of Ghourl and McFarlane (1958). The newly hatched nymphs were placed in candy jars in large numbers. As food, they were given 'baby rabbit pellets $1 *$ which were put in a corner opposite to the water source, which consisted of a $32 \mathrm{ml}$. shell vial filled with distilled water and plugged with aseptic cotton. Strips of paper were put in each jar so as to increase the surface area. The jars were then placed in an incubator set at $35 \pm 1{ }^{\circ} \mathrm{C}$ and having a relative humidity of $50 \%$, which was maintained by a saturated salt solution (O'Brien, 1948). Every week, the water vials were changed and the food supply examined in case some water had come in contact with it. When the nymphs were about half-grown, they were separated into groups of about 20 per jar. As soon as they became adults, they were transferred to another incubator set at $28 \pm_{1}^{\circ} \mathrm{C}$, so they could live longer. In order to obtain eggs, the water vials were removed and fam cups, containing $\frac{1}{2}$ " of moist sterile sand, placed in the jars. These laying dishes

*Ogilvie Flour Mills Co. Ltd., Montreal. 
remained twelve hours with the adults. At the end of that period, they were transferred to 16-ounce ointment jars in which a small piece of moist absorbent cotton was laid to maintain humidity, and the lid was then fixed tightly. It usually took eight days for the eggs to hatch, when the temperature was $35^{\circ} \mathrm{C}$.

b. For Gryllodes sigillatus

The rearing of the stock of Gryllodes sigillatus was slightly different from that described for $A$. domesticus, because these crickets seomed more delicate. As food, they were given a special diet, the formula of which has been given by Ghouri and McFarlane (1958). They could develop and reproduce normally on this diet. However, they had to be kept in an incubator, the temperature of which was $28^{\circ} \mathrm{C}$, because at $35^{\circ} \mathrm{C}$ the adults obtained were not very strong, and lald very few eggs. Another characteristic of G. sigillatus was its habit of cannibalism; it appeared that the males ate the females a few weeks after they have started laying eggs. So, it was advantageous to separate the males from the females when the latter had been fertilized. In all other respects, the same methods were used as for $\underline{A}$. domesticus.

\section{B. TESTING OF THE DIETS}

McFarlane et al. (1959) described a very practical 
method to test the diets used in their preliminary experiments with Acheta domesticus, and it was adopted for this work. Each diet was put in a small shallow boat made of filter paper and placed in 16-ounce ointment jars. Ten young nymphs of A. domesticus (or of Gryllodes sigillatus), which had all hatched within 24 hours, were placed in each jar, so there were 60 insects per diet. As a water source, shell vials of $32 \mathrm{ml}$. capacity were filled with distilled water, plugged with aseptic cotton, and placed, inverted, in the jar opposite to the diet. To increase the surface area, a strip of filter paper $1 \frac{1}{2} "$ wide by $6 "$ long was folded and placed in a rack and were all marked individually. All the diets of the same experiment were placed in the same incubator, set at $35^{ \pm}{ }^{\circ} \mathrm{C}$ and with a relative humidity of 50\%. To keep the humidity constant, a saturated solution of $\mathrm{Ca}\left(\mathrm{NO}_{3}\right)_{2} \cdot 4 \mathrm{H}_{2} \mathrm{O}$ was used in a pie plate (O'Brien, 1948). A fan was kept running continuously so the temperature and humidity remained uniform in every part of the incubator.

\section{CRITERIA}

Every ten days, for a period of 30 days, the number and the average welght of the nymphs were recorded, and also the percent survival at the end of that period. Each adult was weighed individually within 24 hours after maturation, and the average weight of the males and fomales 
of every diet recorded. The average duration of the nymphal stage and the percent survival after the experiment were also calcula ted and registered.

When there was only a small difference between the results of one diet with those of the control, or between the males and females of the same diet, a "t" test was made. Two means were considered to be significantly different when the value of $P<0.05$.

\section{COMPOSITION OF THE DIETS}

Diets may be divided into two general parts, the basic diet, and the vitamin mixture. And the chemicals used in the diets were from the INutritional Blochemicals Corporation', Cleveland, Ohio.

The basic diets used in the three experiments are described in Table II. The ingredients and their proportions were according to the work of McFarland et al. (1959), except for the fat content of basic diets I, II, and III. Basic diet I had one gram of wheat germ o1l, whlle basic diets II and III had respectively 0.1 and $0.5 \mathrm{mg}$ linolelc acid. No fat of any source was added to baslc diet IV.

The four vitamin mixtures which were used for this work are shown in Table I. The first two, "a" and "b", represent approximately double the proportions used by 
Fraenkel et al. (1950), except that in "a" ther is one-tenth as much biotin as in "b". In mixtures "c" and "d", there are approximately double the concentrations used for the German cockroach by Noland et al. (1949), with the exception of blotin in "c" which is one-tenth that in "d".

Each of the four diets of experiment I had one of the vitamin mixtures presented in Table $I$ and are all the sme as far as the basic diet was concerned, which was number $I$.

In the first part of experiment II, where different fat materials were tested, vitamin mixture " $d "$ was used and each one of the four basic diets of Table II. The remainder of the diets in this experiment were composed of basic diet IV and vitamin mixture "d" less one different vitamin in each case. The last experimental diet had only basic diet IV, the vitamin solution being replaced by an equal volume of distilled water.

In experiment III, diet 4 was used, having basic diet I with vitamin mixture "d".

\section{E. PREPARATION OF THE DIETS}

a. Order of mixing

The order of mixing of ingredients has been described by McFarlane et al. (1959). First casein, glucose and salts 
were ground in a mortar. The vitamins were then added in aqueous solution, and grinding continued until every part of the mixture was uniformily wet. The latter was then dried in a dessicator in which the vacuum was made by a water pump. The diet was then ground by means of a mortar and pestle or a Wiley mill to 60 mesh. The cellulose powder was next added and the whole mixed in a ball mill for at least one hour. The cholesterol was dissolved in chloroform and added with fat to the diet, which was then ground in the mortar. The diets were then spread on a sheet of paper so the chloroform could evaporate and finally once more mixed in the ball mill for at least one hour. They were then stored in a refrigerator until used.

b. The vitamin mixtures

Choline chloride, since it is very hygroscopic, was dried as much as possible in the dessicator, and then its percent water content determined. When weighing this vitamin, a welghing bottle had to be used because it took up water so fast that accurate readings were impossible otherwise. No such precaution was necessary for the other vitamins.

The case of choline chloride settled, the rest of the operations in the preparation of the vitamin mixtures were as follows. A solution of folic acid was first made, by dissolving either $5 \mathrm{mg}$ of $1 \mathrm{t}$, in the case of mixtures 
" $\mathrm{a}$ " and "b", or $10 \mathrm{mg}$ in the case of mixtures "c " and "d", in about $50 \mathrm{ml}$ of distilled water, Then, diluted $\mathrm{NH}_{4} \mathrm{OH}$ (1\% solution) was added dropwise until the vitamin was completely dissolved. Then, a biotin solution was made up. $5 \mathrm{mg}$ of this vitamin, in the case of mixtures "a" and "b", or $6 \mathrm{mg}$, in the case of "c" and "d", were dissolved in $100 \mathrm{ml}$ of distilled water. To the proper folic acid solution, the following amounts of blotin solutions were added. For vitamin mixture "a", one $m l$ of the first blotin solution was added; for "b", $10 \mathrm{ml}$ of that same solution were necessary. Two ml of the other biotin solution were added for vitamin mixture "c", and $20 \mathrm{ml}$ for "d", to the corresponding folic acid solution. Then, to each one of the four follc acidbiotin solutions, distilled water was added to make up the volume to $100 \mathrm{ml}$. All the other vitamins were weighed individually and added to the respective folic acid-biotin solution. It should be noted here that when the vitamins, at this stage, were not completely dissolved, the mixtures were heated gently on a water bath, whereupon the vitamins went rapidely into solution and were ready for use.

The technique adopted for the vitamin mixtures in experiment II differed from that just described, since the problem here was that different vitamin mixtures were needed, each one lacking one vitamin, except for diets 5, 6, 7 and 8, which all had a complete vitamin mixture, and diet 19, which 
had no vitamins at all. First of all, each vitamin was dissolved in distilled water in such a concentration that one $\mathrm{ml}$ of the solution contai ned the required amount of the vitamin to be put in the diet. However, riboflavin had to be dissolved by more water; the proportions were such that two $\mathrm{ml}$ of the riboflavin solution were required for the diet. As for Inositol, it was not dissolved, but weighed and added to the vitamin solutions, since very large quantities of it were required. And since each vitamin was needed thirteen times, there boing fourteon vitamin mixtures in all, each quantity in mixture "d" had to be multiplied by 15, at least,

and each quantity of vitamin thus determined was dissolved in the correct volume of distilled water. Fifteen test tubes were lined up, and one $\mathrm{ml}$ of each vitamin solution was added to all the tubes, except to those holding the mixture lacking that specific vitamin, and except also to the last one, corresponding to diet 19, in which no vitamins at all were present. Every time a vitamin was omitted, an equal amount of distilled water replaced it, so the same volume of liquid was added to each diet.

\section{RESULTS}

\section{A. EXPERIMENT I}

For experiment I, the data for the nymphs are presented in Table III, and those for adults in Table IV. 
Diets 2, 3, and 4 gave similar results: their nymphs grew at the same rate, matured in about the same time, and the adults were as heavy and numerous on the one as on the other. However, on diet 4, the nymphal stage of the males was significantly longer than that of the females; this was the only significant difference recorded in these three diets. As far as diet $I$ is concerned, it was clearly inferior to the others of the same experiment. The nymphs did not develop as fast as the others, the average weight of the adults was much inferior, the duration of the nymphal stage very significantly longer and the percent survival much lower.

\section{B. EXPERIMENT II}

Experiment II was divided in two parts; the first four diets were made to test the importance of some lipid materials, wheat germ ofl and linolelc acid, to the house cricket, and the others were to determine which of ten $B$ vitamins were required by this same insect.

a. The importance of Ilpid in the diet

of experiment II, diets $5,6,7$ and 8 were those which differed only by their fat content. At first glance on Table $V$, there seems not to be very much difference in the rate of growth of the insects living on these diets. The average weight of the nymphs was very similar after the first 30-day period, and the same was true of the percent survival. 
Table VI, which gives the results at the end of this experiment, shows the same relation between these four diets. However, one fact was important here: on diet 5 , having one gram of wheat germ oll, the adult females seemed to be significantiy heavier than the males. However, in the average duration of the nymphal stage, the average welght of the adults, and the percent survival, there was no significant variation either from one diet to the other or between adults of opposite sexes on each diet. These diets, however, differed more significantly on the following point: the only eggs that hatched were those laid by females of diet 5 .

b. The importance of $10 \mathrm{~B}$ vitamins to Achete domesticus The major B vitamins seemed all to be necessary for A. domesticus. Diet 9, which has no thiamine, did not give any better growth than diet 19, where all the vitamins were missing; all the nymphs were dead before 20 days. Diet 10, where riboflavin was absent, did permit growth; but after 30 days, the average welght of the nymphs was much lower than those of the control diet, and the same thing was true of the percent survival. Maturation occurred only after a long nymphal period, and the average welght of the adults was clearly below the normal. The absence of nicotinic acid, in diet 11 , resulted in very poor growth during the first 30 days, and no maturation at all. The same results 
issued from the other major B vitamins, pyridoxine and calcium pantothenate: a fow nymphs survived the 30-day perlod, but none could develop enough to mature.

Besides the major $B$ vitamins, choline chloride and biotin proved to be of very great importance. Diet 14, lacking choline chloride, had no nymphs that survived to 30 days. Without biotin, on diet 18, the nymphs lived through the first 30-day period, but grew very poorly. However, after a long nymphal stage, a few of them matured.

The omission of inositol from diet 15 definitely slowed down the rate of development of A. domesticus. Moreover, the adults were very inferior to those of the control, diet 8 , in average weight as well as in number. The nymphal stage, even though significantly longer than that of diet 8, was still shorter in comparison with that of diets 10 and 18, which lacked riboflevin and blotin.

Follc acid seemed to have had only a very slight effect on growth of the house cricket. The nymphs deprived of this vitamin did not grow as fast as those fed the complete diet. It also took them a little longer to mature, but the average weight of the adults was normal. However, after the 30-day period, a high rate of mortality was noticed; the percent survival dropped from 71 , at 30 days, to 43 , at the end of the experiment. 
Slight effects resulted from the omission of p-aminobenzoic acid, and the only significant one was the length of the nymphal stage which was longer than that of the control. There was also a tendency for the males to be heavier than the females.

\section{REPLICATE OF EXPERIMENT II}

The results of this experiment will be found in Tables VII and VIII. They are similar to those of experiment II, with a few exceptions only, which will be explained here.

In the first part of the experiment, where the diets differed by their content of fat (diets 20, 21, 22, and 23), one thing is to be pointed out: diet 23, lacking fat completely, had a nymphal stage significantly longer than that on diets 20,21 and 22 , which have either wheat germ oil or linoleic acid in different concentrations.

As far as vitamins are concerned, diet 25, without riboflavin, had a signiflcant difference between the average duration of the nymphal stage of the males and females.

The diets without folic acid or p-aminobenzolc acid did not give a nymphal stage duration significantly longer than that of the control, although there was a tendency in this direction. Diet 32 , without follc acid, also had a very low percent survival. 


\section{EXPERIMENT III}

The data for experiment III are presented in Tables IX and $X$. The crickets which were fed baby rabbit pellets grew much faster than the others on an artificial diet. Moreover, the adult welght was higher, and the nymphal stage duration definitely shorter. The percent survival on the artificial diet was apparentiy better than on the other diet.

\section{DISCUSSION AND CONCLUSIONS}

\section{A. EXPERIMENTT I}

As may be seen from Table $I$, the vitamin concentrations in mixtures "a", "b", "c" and "d" were quite high. These concentrations were decided upon McFarlane et al. (1959) which had shown that the vitamin mixture of Fraenkel et al. (1950) resulted in inferior growth and development of the house cricket, whereas double the concentrations proved to be very satisfactory. However, McFarlane et al. (1959) included in their diet one-tenth the biotin that they had indicated (personal communication).

In this experiment, diet 1 corresponded to the diet of McFarlane et al. (1959) while diet 2 contained the vitamin mixture of Fraenkel et al. (1950) in double concentrations. Since diet 1 was definitely inferior to diet 2, it was clear 
that its biotin was not present in large enough quantity. Diets 3 and 4 were as satisfactory as diet 2 on all respects. The difference in biotin had no effect at all on the crickets; so, vitamin mixture "c" had enough biotin.

Vitamin mixture "d" was used as the basis for the study of the vitamin requirements of the house cricket because diet 4 gave the heaviest adults and the highest percent survival. Even though these results were not significantly better than those of diets 2 and 3 , they decided the author for the choice of that specific mixture.

It should be noted here that it is quite possible that the vitamin mixture of Noland et al. (1949a) would be as sufficient as vitamin mixture "d", because its vitamin concentrations were higher then those suggested by Fraenkel et al. (1950) for the stored food products insects. However, the comparison between them was not made in this experiment.

\section{B. EXPERIMENT II AND ITS REPLICATE}

\section{THE IMPORTANCE OF THE LIPIDS}

McFarlane et af. (1959) found that the diet with wheat germ ofl resulted in a shorter nymphal stage of $A$. domesticus and that the females were significantly heavier than the males. But as far as the present work is concerned, this effect was not shown as clearly. In experiment II, 
diet 5, with wheat germ oil, did give females with a higher average weight than the males, but no such difference was found in the replicate. Moreover, in experiment II, the Insects of diets $5,6,7$ and 8 had a nymphal stage of the same length, while in the repeat, the diets with wheat germ oil or Inolelc acid had a maturation much faster than diot 23, which was devolded of fat. Within the diets, McFarlane et al. (1959) did not find any differences between the nymphal stage duration of the males and females, while, in this work, on diet 6 , the males took significantly longer than the females to mature; however, no such effect was observed with diet 21 , which was 1dentical to diet 6.

So, it appears that fat has not a very important effect on nymphal growth of the house cricket, because any influence noted in the original experiment did not occur in the repeat, and vice versa; but it must be said that a source of lipid in the diets has a tendency to make them more efficient.

As far as linoleic acid is concerned, it seemed to be as good as wheat germ oll for growth, because diets having it did not differ from the control. But the diets with wheat germ oll were shown to be more efficlent for the hatching of the eggs, since young nymphs were obtained from the eggs laid by insects fed diet 5. No hatching could be recorded from any other diet, even those having linolelc acid. 


\section{THE IMPORTANCE OF TEN B VITAMINS}

It is clear from the data obtained that Acheta domesticus requires most of the B-group vitamins. The latter are generally accepted to be the only ones important for growth of insects. Nevertheless, there is much variation from one specles to the other in their needs for these factors. A picture of the situation has been given in the first chapter of this work.

a. Inositol

Acheta domesticus proved to be different from most of the other insects by the effect of the omission of inositol on the growth of its nymphs. The latter developed poorly, took longer to mature and the adults obtained were of lower weight, compared to those of the control. So it is clear that inositol is of importance to house cricket nutrition, even if not required absolutely. This vitamin has been shown to be required by two insects only: Anthononus grandis (Vanderzant, 1959) and Periplaneta americana (Forgash, 1958).

b. p-Aminobenzoic acid

The results observed in the absence of p-aminobenzoic acid do not go against the conclusions of McFarlane et al. (1959); this vitamin has a tendency to improve the diet containing it, even if not significantly. The only 
other insect for which this vitamin was shown beneficial, was Aedes aegypti; it did not improve growth, but helped ecdysis (Singh and Brown, 1957).

c. The major B vitamins

of the major $B$ vitamins, only riboflavin could be omitted without any drastic effects. But in this case, growth was slow and the adults obtained not only were fewer, but lighter than those fed the complete diet. This situation has also been found with Tineola bisselliella (Fraenkel and Blewett, 1945), Chilo suppressalis (Ishii and Urushibara, 1954), and Blatella germanica (Noland et al., 1949b). Two insects seemed to develop normally in the absence of this vitamin: Ephestia kuehniella (Fraenkel and Blewett, 1946) and Periplaneta americana (Sieburth and McLaren, 1953). However, in the case of the american cockroach, a high rate of mortality was observed after 90 days of nymphal life (Sieburth and McLaren, 1953).

This situation is about the same with all insects not harboring symbionts: they all require the major $B$ vitamins, but, in most cases, there is one or more of these vitaming which seems less improtant, its omission causing but a delaying effect on growth, a higher percentage of mortality or the formation of small adults. But they always are needed for optimal growth, which is not true of the other B vitamins. 
d. Folic acid

Among the insects, there is very much variation In the need for folic acld; some do not need it or even do well without it, whereas others cannot survive in its absence. As far as the house cricket is concerned, folic acid seems not to be required badly for nymphal growth, 1ts omission resulting only in a slight delay of maturation. However, for a normal percent survival, this vitamin is of some importance. These findings correspond to what has been found with the majority of insects on their folic acid requirement. The only insects which do require this growth factor are: T. confusum (Fraenkel and Blewett, 1943a, 1943c), Dermestes vulpinus (Cooper and Fraenkel, 1952), E. elutella (Fraenkel and Blewett, 1946), $\underline{H}$. antiqua (Friend and Patton, 1956), $\underline{P}$. americana (Sieburth and McLaren, 1953), and $\underline{\mathrm{C}}$ suppressalis (Ishi1 and Jrushibara, 1954).

e. Choline chloride

Acheta domesticus cannot survive without choline chloride. After thiamine, it appeared to be the most important growth factor for this insect. Like folic acid, it is not generally required by insects; in most cases, It has a delaying effect on growth and sometimes it is not required at all. 
Choline, not being a true B vitamin, is certainly required in larger amounts than the other vitamins. However, the concentrations used here were much too high, but no detrimental effects resulted from that situation, as was the case with Palorus ratzoburg1 (Cooper and Fraenkel, 1952), which has an optimal requirement for this vitamin. Diet 2, which has $100 \mathrm{mg}$ of choline chloride, gave as good results as diets 3 and 4 , which have $200 \mathrm{mg}$ of 1 t.

f. Biotin

Biotin is essential for the nymphal growth of the house cricket, and, from this work, an estimate of the minimal requirements can be made. Diet 1 , which had only $0.005 \mathrm{mg}$ blotin, did permit quite satisfactory growth, even if significantly inferior to the other diets of experiment I. And diet 3, with $0.012 \mathrm{mg}$ of this vitamin, gave as good results as were obtained with any diet. Therefore, the minimal needs of A. domesticus for biotin Ile between these two concentrations. So, the amounts used in experiment II exceed very much the needs of this insect.

g. Conclusion

Although elght vitamins may be said to be required by A. domesticus, in the sense that omission of any one of them results in poorer growth and survival, in the absence 
of any of them there still was some growth, and this depended on the vitamin missing from the diet. House (1954) suggested the following possible explanations for this common observation in his study of Pseudosarcophaga affinis: Iimited biosynthesis, or production of good stores of these vitamins in the egg itself, or the use of other ingredients by the organism, such as, for instance, methionine instead of choline as a supply of methyl groups. In the present experiment, another factor may have led to more growth than that due to the different causes just mentioned, and this was that the crickets had the habit of eating each other. When one of them was getting weak, the others devoured it quickly. So, in this way, on each diet, an extra source of nutrients was made available to these insects. The significance of this fact should be straightened up experimentaliy, by rearing the crickets individually. There might be more drastic effects as a result of the lack of the different growth factors, but there would probably be no changes in the general conclusions already obtained in this work.

\section{EXPERIMENT III}

This experiment showed that Gryllodes sigillatus could be reared on an artificial diet so its requirements for growth may be determined. However, growth was not as 
successful as on the control diet consisting of baby rabbit pellets. The factors responsible for this difference are still unknow, but they are certainly not essentlal, since Gryllodes could develop quite reasonably without them. The low percent survival on the control was probably caused by a certain lack in the uniformity of the food which had been made in great quantities by a company, and from one bag to the other, there might be some differences which could have some effects on the crickets, but not on the rabbits.

\section{SUMMARY}

This work, in its first part, gave a review of the information published on the vitamin requirements of insects. It was stated that insects have needs for the $B$ vitaming only, of which inositol, p-aminobenzolc acid, and $B_{12}$ are generally not required. The major B vitamins are the most important: thiamine, riboflavin, nicotinic acid, pyridoxine, and pantothenic acid. Insects vary considerably in their needs for B vitamins; no two species have exactly the same requirements and it is not possible to say that any particular vitamin is always required.

A preliminary experiment was carried out to see which of four different $B$ vitamin mixtures would give the best growth. The diet having the vitamin mixture suggested 
by Mc Farlane et al. (1959) was shown not to be as efficient as the other three. So, the mixture giving double the concentrations used by Noland et al. (1949a) was adopted as the basis for the experiment on the vitamin requirements.

The aim of this work was principally to determine the effect of single omission of ten $B$ vitamins on the growth and derelopment of the house cricket, Acheta domesticus. Very poor growth or no growth at all and no maturation were recorded on the diets lacking thiamine, nicotinic acid, calcium pantothenate, pyridoxine, or choline chloride. Only a few insects survived in the absence of biotin. Lack of riboflavin or inositol gave similar effects: growth was retarded significantly and a low percent survival was recorded; moreover, the adults obtained were of a lower welght than the control. Folic acid was not required for growth, but poor survival occurred when it was omitted. No significant effect was noticed when p-aminobenzoic acid was absent from the diet.

\section{As far as lipids were concerned, no apparent} difference existed between the diets having wheat germ oil, Inoleic acid, or no fat at all. In the latter case, there might be a tendency for a longer nymphal stage.

Gryllodes sigillatus was tested on an artificial diet. Growth and development seemed reasonable, but were poorer than on the control of baby rabbit pellets. 
VIII. BIBLIOGRAPHY

Beck, S.D.

1953. Nutrition of the European corn borer, Pyrausta nubilalis (Bbn.). III. An unidentified dietary factor required for larval growth. J. Gen. Physiol. 36: 317-327.

Beck, S.D., J.H. Lilly, and J.F. Stauffer.

1949. Nutrition of the European corn borer, Pyrausta nubilalis (Hon.). I. Development of a satisfactory purified diet for larval growth. Ann. Ent. Soc. Am. 42: 483-496.

Begg, M., and F.W. Robertson.

1950. The nutritional requirements of Drosophila melanogaster. J. Expt1. Bid. 26: 280-387.

Blewett, M. and G. Fraenkel.

1944. Intracellular symbiosis and vitamin requirements of two insects, Lasioderma serricorne and Sitodrepa panicea. Proc. Roy. Soc. (London), B. 132: 212-221.

Bosticco, A. and M. Arnaudo.

1955. Att1. Soc. Ital. Sci. Vet. 8: 272-275. (Cited In Ann. Rev. Ent. 3: 75-86). 
Brooks, M.A. and A.G. Richards.

1955. Intracellular symbiosis in cockroaches. I. Production of aposymbiotic cockroaches. Biol. Bull. 109: 22-39.

Brust, M. and G. Fraenkel.

1955. The nutritional requirements of the larvae of the blowfly phormia regina (Meig.). Physiol. Zool. 28: 186-204.

Carter, H.E., P.K.Battacharyya, K.R.Weidman and G.Fraenkel. 1952. The identity of vitamin $B_{T}$ with carnitine. Arch. Biochem. and Biophys. 35: 241-242.

Charbonneau, R. and A. Lemonde.

1960. Unidentified growth factors in brewer's yeast. I. Necessity of these factors for Tribolium confusum Duval. Can. J. Zool. 38: 87-90.

Cooper, M.I. and G. Fraenkel.

1952. Nutritive requirements of the small-eyed flour beetle, Palorus ratzeburgi Wissman (Tenebrionidae, Coleoptera). Physiol. Zool. 25: 20-28.

Elliot, K.R.

1954. Development of a synthetic diet for the larvae of the southern armyworm, Prodenia eridania (Cramer). (Master's thesis, Univ. Western Ontario, London, Ontario, Canada). (Cited in Ann. Rev. Ent. 3: $57-74)$. 
Forgash, A.J.

1958. The effect of inositol on growth, survival, and maturation in Periplaneta americana $I$. Ann. Ent. Soc. Am. 51: 406-409.

Fraenkel, G.

1949. Unidentifled vitamins of the B complex required by certain insects. Federation Proc. 8: 382.

Fraenkel, G.

1951. The nutritional requirements of insects for known and unknown vitamins. Trans. IXth Int. Congr. of Ent., Amsterdam, Aug. 17-24. I: $277-280$

Fraenkel, G.

1951. Arch. Blochem, and Biophys. 34: 468. (Cited in Ann. Rev. Ent. 1: 17-44).

Fraenkel, G.

1959. A historical and comparative survey of the dietary requirements of insects. Ann. N.Y. Acad. Sci. $77: 267-274$.

Fraenkel, G. and M. Blewett.

1942. Biotin, $B_{1}$, riboflavin, nicotinic acid, $B_{6}$, and pantothenic acid as growth factors for insects. Nature 150: 177-178. 
Fraenkel, G. and M. Blewett.

1943a. Vitamins of the B group required by insects. Nature 151: 703-704.

Fraenkel, G. and M. Blewett.

1943b. Intracellular syrbionts of insects as a source of vitamins. Nature 152: 506-507.

Fraenkel, G. and M. Blewett.

1943c. The vitamin B complex requirements of several insects. Biochem. J. (London) 37: 686-692.

Fraenkel, G. and M. Blewett.

1945. Linoleic acid, vitamin $E$, and other fat soluble substances in the nutrition of certain insects, Ephestia kuehniella, E. elutella, E. cautella, and Plodia interpunctella (Lep.). J. Exptl. B101. 22: 172-190.

Fraenkel, G. and M. Blewett.

1945. The dietetics of the clothes moth, Tineola bisselliella Hum. J. Expt1. Biol. 22: 156-161.

Fraenkel, G. and M. Blewett.

1946. The dietetics of the caterpillars of three Ephestia spocies Ephestia kuehniella, E. cautella, and a closely related species Plodia Interpunctella. J. ExptI. Biol. 22: 162-171. 
Fraenkel, G., M. Blewett, and M. Coles.

1948. A new vitamin of the $B$ group and 1ts relation to the follc acid group, and other anti-anaemia factors. Nature 161: 981-983.

Fraenkel, G., M. Blewett, and M. Coles.

1950. The nutrition of the mealworm, Tenebrio molitor L. (Tenebrionidae, Coleoptera). Physiol. Z001. 23: 92-108.

Fraenkel, G. and P.I. Chang.

1954. Manifestations of a vitamin $B_{T}$ (carnitine) deficiency in the larvae of the mealworm, Tenebrio molitor I. Physiol. Zool. 27: 40-56.

French, E.W.

1954. The requirements of Tribolium confusum for known and unknown vitamins (Doctoral thesis, Univ. of Illinois, Urbana, IIl., 1954). (Cited in Ann. Rev. Ent. 1: 17-44).

French, E.W. and G. Fraenkel.

1954. Carnitine (Vitamin $\mathrm{B}_{\mathrm{T}}$ ) as a nutritional requirement for the confused flour beetle. Nature 173:173.

Friend, W.G.

1955. Problems in nutritional studies on phytophagous insects. Ann. Rept. Entomol. Soc. Ont. 86: 13-17. 
Friend, H.G.

1958. Nutritional requirements of phytophagous insects. Ann. Rev. Ent. 3: 57-74.

Friend, W.G. and R.L. Patton.

1956. Studies on vitamin requirements of larvae of the onion maggot, Hylemya ant1qua $(\mathrm{Mg} \cdot)$, under aseptic conditions. Can. J. Zool. 34: 152-162.

Frobrich, G.

1953. Naturwissenschaften 40: 344. (C1ted in Ann. Rev. Ent. 1: $17-44)$.

Furton, J.S. and S. Simmonds.

1953. General Blochemistry. New York, John Wiley and Sons.

Ghour1, A.S.K. and J.E. McFarlane.

1958. Observations on the development of crickets. Can. Ent. 90: 158-165.

Golberg, I., B. DeMeilion, and M. Lavoipierre.

1945. The nutrition of the larvae of Aedes aegypti

L. II. Essential water soluble factors from jeast. J. Exptl. Biol. 21: 90-96.

Gordon, H.T.

1959. Minimal nutritional requirements of the German roach Blatella germanica L. Ann. N.Y. Acad. Sc1. $77: 290-351$ 
Hagen, K.S.

1958. Honeydew as an adult fruit fly diet affecting reproduction. Proc. Xth, Ent. Congr. Ent. Montreal, Aug. 17-25. 3: 25-30.

Hinton, T., D.T. Noyes, and J. Ellis.

1951. Amino acids and growth factors in a chemically defined medium for Drosophila. Physiol. Zool. $24: 335-353$.

House, H.L.

1954. Nutritional studies with Pseudosarcophaga affinis (Fall.), a dipterous parasite of the spruce budworm, Choristoneura fumiferana (Clem.). II. Effects of eleven vitamins on growth. Can. J. Zool. 32: 342-350.

House, H.L.

1955. Nutritional requirements and artificial diets for insects. Ann. Rept. Ent. Soc. Ont. 86: 5-21.

House, H.L.

1958. Nutritional requirements of insects associatid with animal parasitism. Exptl. parasitol. 7: 555.

House, H.L.

1958. The nutrition of insects with particuliar reference to entomophagous parasitism. Proc. Xth Intern. Congr. Ent. Montreal (1956). 2: 139-143. 
House, H.L. and R.I. Patton.

1949. Nutritional studies with Blatella germanica

(I.) reared under aseptic conditions. I.

Equipment and techniques. Can. Ent. 81: 94-100.

House, H.L. and J.S. Barlow.

1958. Vitamin requirements of the housefly, Musca domestica L. (Diptora, Muscida $\theta$ ). Ann. Ent. Soc. Am. 51: 299-302.

Ishil, S. and H. Urushibara.

1954. On fat soluble and water soluble growth factors required by the rice stem borer, Chilo simplex Butler. Bull. Natl. Inst.Agr. Sci. (Japan). 4: $109-133$

Legay, J.M.

1958. Recent advances in s11kworm nutrition. Ann. Rev. Ent. 3: 75-86.

Lemonde, A. and R. Bernard.

1951. Nutrition des larves de Tribolium confusum Duval. I. Recherche d'un regime synthetique basal satisfaisant. Can. J. Zool. 29: 71-83.

Lemonde, A. and R. Bernard.

1953. Aspects nutritifs des larves de Stegobium paniceum L. (Anobildae) et d'oryzaephilus surinamensis I. (Cucujidae). Nat. Can. 80: 125-142. 
Ilpke, H. and G. Fraenkel.

1956. Insect nutrition. Ann. Rev. Ent. 1: 17-44.

Magis, N.

1954. Arch. Intern. Physiol. 62: 505. (Gited in Ann. Rev. Ent. 1: 17-44).

MeFarlane, J.E., B. Neilson, and A.S.K. Ghouri.

1959. Artificial diets for the house cricket Acheta domesticus (L.). Can. J. Zool. 37: 913-916.

McGinnis, A.J., R.W. Newburgh, and V.H. Cheldelin.

1956. Nutritional studies on the blowfly Phormia regina. J. Nutrition. 58: 309-323.

Noland, J.L., J.H. Lilly, and C.A. Baumann.

1949a. A laboratory method for rearing cockroaches and its application to dietary studies on the German roach. Ann. Ent. Soc. Am. 42: 63-70.

Noland, J.L., J.H. Lilly, and C.A. Baumann.

1949b. The vitamin requirements of the cockroach Blatella germanica. Ann. Ent. Soc. Am. 42: 154-164.

O'Brien, F.E.M.

1948. The control of humldity by saturated salt solutions. J. Sci. Instrum. 25: 73-76. 
Offhaus, $K$.

1952. Der Vitaminbedarf des ReismehlkHfers Tribolium confusum Duval. Z. Vitamin-, Hormon- $u$.

Fermentforsch. 4:555-563. (Cited in Ann. Rev. Ent. 1: 17-44).

Pont, N.C. and G. Fraenkel.

1950. The function of the symbiot1c yeasts of two insect species, Lasioderma serricorne F. and

Stegobium (Sitodrepa) paniceum I. Science $112: 498-500$.

Richards, A. O. and M.A. Brooks.

1958. Internal symbionts in insects. Ann. Rev. Ent. 3: 37-56.

Sang, J.H.

1956. The quantitative nutritional requirements of Drosophila melanogaster. J. Exptl. Biol. $33: 45-72$.

Sleburth, J.F. and B.I. McLaren.

1953. Growth studies with cockroach Periplaneta americana (Iinn.), fed vitamin deficient diets substituted with corresponding antivitamins. Ann. Ent. Soc. Am. 46: 43-48. 
54.

Singh, K.R.P. and A.W.A. Brown.

1957. Nutritional requirements of Aedes aegzpti

L. J. Insect Physiol. 1: 199-200.

Takahashi, J.

1955. J. Agr. Chem. Soc. Japan. 29: 711-715.

(C1ted in Ann. Rev. Ent. 3: 75-86).

Trager, $W$.

1947. Insect nutrition. Biol. Revs. Cambridge Phil. Soc. 2.2: $148-177$.

Vanderzant, E.S.

1959. Inositol: an indispensable dietary requirement for the boll weevil. J. Ec. Ent. 52: 1018-1019.

Vanderzant, E.S. and R. Reiser.

1956. Studies on the nutrition of the pink bollworm using purified casein media. J. Ec. Ent. 49: $454-458$.

Yoshida, T.

1955. Bull. Sericult. Expt1. Sta. (Tokyo), 14: 351-426. (C1ted in Ann. Rev. Ent. 3: 75-86). 
Table I. Composition of the vitamins mixtures.

Vitamin Mixtures Components in mgs per Diet.

\begin{tabular}{|c|c|c|c|c|}
\hline Vitamin & $\underset{\mathbf{a}}{\text { itamin Mixture }}$ & $\underset{b}{\text { Vitamin Mixture }}$ & Vitamin $_{c}$ Mixture & ${ }_{\mathrm{d}}^{\text {Vitamin Mixture }}$ \\
\hline Thiamine & 5.0 & 5.0 & 2.4 & 2.4 \\
\hline Riboflevin & 2.5 & 2.5 & 3.6 & 3.6 \\
\hline Nicotinic acid & 10.0 & 10.0 & 20.0 & 20.0 \\
\hline Pyridoxine & 2.5 & 2.5 & 3.2 & 3.2 \\
\hline Ca pantothenate & 5.0 & 5.0 & 8.0 & 8.0 \\
\hline Choline chloride & 100.0 & 100.0 & 200.0 & 200.0 \\
\hline Inositol & 50.0 & 50.0 & 400.0 & 400.0 \\
\hline $\begin{array}{r}\text { p-Aminobenzoic } \\
\text { acid }\end{array}$ & 5.0 & 5.0 & 10.0 & 20.0 \\
\hline Folic acid & 0.5 & 0.5 & 1.0 & 1.0 \\
\hline Blotin & 0.005 & 0.05 & 0.012 & 0.12 \\
\hline
\end{tabular}

Note:

(1) The vitamin mixtures " $a$ " and "b" differ by their biotin content only; "b" has ten times more blotin than "a".

(2) Vitamin mixture "d" has ten times more biotin than "c". 
Table II. Composition of the basic diets.

\begin{tabular}{|c|c|c|c|c|}
\hline Components & 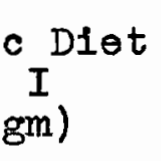 & $\begin{array}{c}\text { Basic Diet } \\
\text { II } \\
(\mathrm{gm})\end{array}$ & $\begin{array}{c}\text { Basic Diet } \\
\text { III } \\
(\mathrm{gm})\end{array}$ & $\begin{array}{c}\text { Basic Diet } \\
\text { IV } \\
\text { (gm) }\end{array}$ \\
\hline Casein & 40 & 40 & 40 & 40 \\
\hline Glucose & 20 & 20 & 20 & 20 \\
\hline $\begin{array}{l}\text { Cellulose powder } \\
\text { (alphacel) }\end{array}$ & 30 & 30 & 30 & 30 \\
\hline Cholesterol & 1 & 1 & 1 & 1 \\
\hline $\begin{array}{l}\text { SaIt mixtur } \theta \\
\text { U.S.P. XIV }\end{array}$ & 2 & 2 & 2 & 2 \\
\hline Wheat germ oil & 1 & 0 & 0 & 0 \\
\hline Iinolelc acid & 0 & 0.1 & 0.5 & 0 \\
\hline Total & 94.0 & 93.1 & 93.5 & 93.0 \\
\hline
\end{tabular}


Table III. Experiment I. Nymphal growth during the first 30 days.

\begin{tabular}{|c|c|c|c|c|c|c|c|c|c|}
\hline Expt1. & Compo & ition & Numbe & or and Average & & sht of the & Nymphs aft & & Percent \\
\hline No. & $\begin{array}{l}\text { Basic } \\
\text { Diet }\end{array}$ & $\begin{array}{l}\text { Vitamin } \\
\text { Mixtur }\end{array}$ & No. & $\begin{array}{l}\text { Days } \\
\text { Av. Wt. } \\
\text { (mg) }\end{array}$ & No. & $\begin{array}{l}\text { Days } \\
\text { Av. Wt. } \\
\text { (mg) }\end{array}$ & No. & $\begin{array}{l}\text { Days } \\
\text { Av. Wt. } \\
\text { (mg) }\end{array}$ & 30 Days \\
\hline 1 & $I$ & a & 58 & 7.4 & 56 & 34.8 & 48 & 91.6 & 80 \\
\hline 2 & $I$ & $\mathrm{~b}$ & 58 & 9.1 & 58 & 54.0 & 53 & 186.9 & 88 \\
\hline 3 & $I$ & c & 53 & 8.9 & 53 & 54.4 & 51 & 187.1 & 85 \\
\hline 4 & $I$ & $\mathrm{~d}$ & 58 & 8.6 & 57 & 52.8 & 56 & 178.8 & 93 \\
\hline
\end{tabular}


Table IV. Experiment I. Average weight of adults, average duration of the nymphal stage, and percent survival.

\begin{tabular}{|c|c|c|c|c|c|c|c|}
\hline Expt1. & Ad & Lt Males Obtaine & & Ad & Lt Females Obtai & led & Percent Survival \\
\hline No. & No. & $\begin{array}{l}\text { Av. Duration } \\
\text { of the Nymphal } \\
\text { Stage (days). }\end{array}$ & $\underset{(\mathrm{mg})}{\mathrm{Av}, \mathrm{Wt}}$ & No. & $\begin{array}{l}\text { Av. Duration } \\
\text { of the Nymphal } \\
\text { Stage (days) }\end{array}$ & $\begin{array}{c}A v \cdot \text { Wt. } \\
(\mathrm{mg})\end{array}$ & \\
\hline 1 & 22 & 55.4 & 225.4 & 17 & 55.1 & 246.0 & 65 \\
\hline 2 & 34 & 44.8 & 313.0 & 16 & 43.4 & $337 \cdot 3$ & 83 \\
\hline 3 & 32 & 44.8 & 316.8 & 15 & 45.0 & 331.2 & 78 \\
\hline 4 & 20 & 49.9 & 351.5 & 30 & 43.7 & 338.3 & 83 \\
\hline
\end{tabular}


Table V. Experiment II. Nymphal growth during the first 30 days.

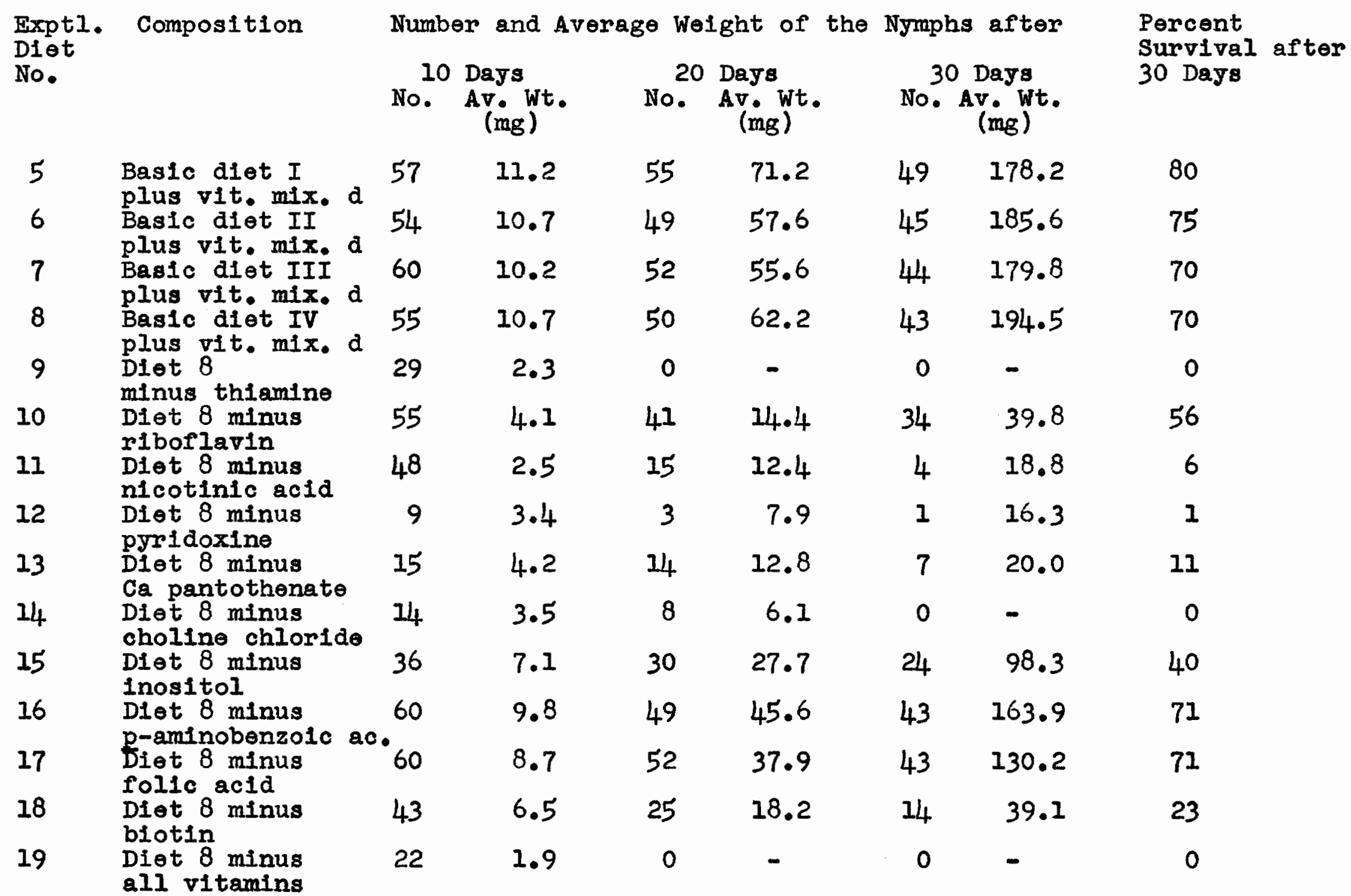


Table VI. Experiment II. average weight of adults, average duration of the nymphal stage, and percent survival.

\begin{tabular}{|c|c|c|c|c|c|c|c|}
\hline Exptl. & & alt Males Obtair & & & ult Females Obts & Ined & Percent $s$ \\
\hline No. & No. & $\begin{array}{l}\text { Av. Duration } \\
\text { of the Nymphal } \\
\text { Stage (days) }\end{array}$ & $\underset{(m g)}{\text { Av. }}$ Wt. & No. & $\begin{array}{l}\text { Av. Duration } \\
\text { of the Nymphal } \\
\text { Stage (days) }\end{array}$ & $\underset{\text { (mg) }}{\text { Avt. }}$ & \\
\hline 5 & 25 & 40 & 276.9 & 14. & 41 & 320.9 & 63 \\
\hline 6 & 21 & 44 & 288.1 & 20 & 40 & 308.7 & 68 \\
\hline 7 & 19 & 42 & 284.6 & 20 & 41 & 300.1 & 62 \\
\hline 8 & 22 & 41 & 283.5 & 19 & 40 & 287.7 & 67 \\
\hline 9 & 0 & - & - & 0 & - & - & 0 \\
\hline 10 & 10 & 72 & 196.8 & 6 & 66 & 211.2 & 26 \\
\hline 11 & 0 & - & - & 0 & - & - & 0 \\
\hline 12 & 0 & - & - & 0 & - & - & 0 \\
\hline 13 & 0 & - & - & 0 & - & - & 0 \\
\hline $\mathrm{IH}_{4}$ & 0 & - & - & 0 & - & - & 0 \\
\hline 15 & 6 & 48 & 184.1 & 9 & 45 & 228.6 & 25 \\
\hline 16 & 16 & 49 & 310.5 & 19 & 41 & 290.4 & 58 \\
\hline 17 & $\mathrm{IH}_{4}$ & 48 & 303.7 & 12 & 46 & 283.4 & 43 \\
\hline 18 & 3 & 58 & 247.4 & 3 & 73 & 240.2 & 10 \\
\hline 19 & 0 & - & - & 0 & - & - & \\
\hline
\end{tabular}


Table VII. Repeat of experiment II. Nymphal growth during the first 30 days.

\begin{tabular}{|c|c|c|c|c|c|c|c|c|}
\hline $\begin{array}{l}\text { ExptI. } \\
\text { Diet }\end{array}$ & Composition & Numbe & or and Average & Weig & zht of the & Nymphs & after & \\
\hline No. & & No. & $\begin{array}{l}\text { Days } \\
\text { Av. Wt. } \\
(\dot{m g})\end{array}$ & No. & $\begin{array}{l}\text { Days } \\
\text { Av. Wt. } \\
(\dot{m g})\end{array}$ & No. & $\begin{array}{l}\text { Days } \\
\text { Av. Wt. } \\
\text { (mg) }\end{array}$ & $\begin{array}{l}\text { Percent } \\
\text { Survival after } \\
30 \text { Days. }\end{array}$ \\
\hline 20 & $\begin{array}{l}\text { Basic diet } I \\
\text { pilus vit. mix. d }\end{array}$ & 50 & 10.1 & 49 & 69.9 & 45 & 206.1 & 75 \\
\hline 21 & $\begin{array}{l}\text { Basic diet II } \\
\text { plus vit. mix. d }\end{array}$ & 48 & 11.1 & 47 & 67.1 & 46 & 170.6 & 76 \\
\hline 22 & $\begin{array}{l}\text { Basic diet III } \\
\text { plus vit. mix. d }\end{array}$ & 43 & 10.7 & 41 & 57.6 & 40 & 168.6 & 66 \\
\hline 23 & $\begin{array}{l}\text { Basic diet IV } \\
\text { plus vit. mix. d }\end{array}$ & 47 & 9.3 & 43 & 49.0 & 42 & 131.9 & 70 \\
\hline 24 & $\begin{array}{l}\text { Diet } 23 \\
\text { minus thiamine }\end{array}$ & 18 & 2.1 & 1 & 0.9 & 0 & - & 0 \\
\hline 25 & $\begin{array}{l}\text { Diet } 23 \text { minus } \\
\text { riboflavin }\end{array}$ & 54 & 5.9 & 52 & 16.5 & 51 & 35.5 & 85 \\
\hline 26 & $\begin{array}{l}\text { Diet } 23 \text { minus } \\
\text { nicotinic acid }\end{array}$ & 38 & $4 \cdot 1$ & 12 & 6.3 & 4 & 10.3 & 6 \\
\hline 27 & $\begin{array}{l}\text { Diet } 23 \text { minus } \\
\text { pyridoxine }\end{array}$ & 31 & 3.8 & 21 & 6.0 & 9 & 10.6 & 15 \\
\hline 28 & $\begin{array}{l}\text { Diet } 23 \text { minus } \\
\text { Ca pantothenate }\end{array}$ & 21 & 6.4 & 13 & 14.1 & 6 & 22.5 & 10 \\
\hline 29 & $\begin{array}{l}\text { Diet } 23 \text { minus } \\
\text { choline chloride }\end{array}$ & 23 & 2.6 & 12 & 3.0 & 4 & 4.8 & 6 \\
\hline 30 & $\begin{array}{l}\text { Diet } 23 \text { minus } \\
\text { Inositol }\end{array}$ & 41 & 6.9 & 35 & 27.5 & 28 & 81.3 & 46 \\
\hline 31 & $\begin{array}{l}\text { Diet } 23 \text { minus } \\
\text { p-aminobenzolc ac. }\end{array}$ & 51 & 10.7 & 46 & 52.5 & 44 & 166.8 & 73 \\
\hline 32 & $\begin{array}{l}\text { Diet } 23 \text { minus } \\
\text { folic acid }\end{array}$ & 50 & 9.3 & 43 & 38.6 & 21 & 103.7 & 35 \\
\hline 33 & $\begin{array}{l}\text { Diet } 23 \text { minus } \\
\text { biotin }\end{array}$ & 41 & $7 \cdot 2$ & 22 & 15.8 & 18 & 26.8 & 30 \\
\hline 34 & $\begin{array}{l}\text { Diet } 23 \text { minus } \\
\text { all vitamins }\end{array}$ & 17 & 2.4 & 4 & 4.1 & 0 & - & 0 \\
\hline
\end{tabular}


Table VIII. Repeat of experiment II. Average weight of adults, average duration of the nymphal stage, and percent survival.

\begin{tabular}{|c|c|c|c|c|c|c|c|}
\hline Expt1. & & Lt Males Obtaine & & & alt Females Obts & ned & Percent \\
\hline $\begin{array}{l}\text { No. } \\
\text { No. }\end{array}$ & No. & $\begin{array}{l}\text { Av. Duration } \\
\text { of the Nymphal } \\
\text { Stage (days) }\end{array}$ & $\underset{(m g)}{A V} \cdot{ }^{t}$. & No. & $\begin{array}{l}\text { Av. Duration } \\
\text { of the Nymphal } \\
\text { Stage (days) }\end{array}$ & $\underset{(\dot{m g})}{\mathrm{Av}}$ & \\
\hline 20 & 18 & 42 & 282.2 & 26 & 40 & 309.8 & 73 \\
\hline 21 & 19 & 42 & 280.2 & 20 & 42 & 283.9 & 62 \\
\hline 22 & 15 & 44 & 272.6 & 22 & 41 & 311.5 & 61 \\
\hline 23 & 16 & 47 & 247.4 & 19 & 45 & 293.4 & 58 \\
\hline 24 & 0 & - & - & 0 & - & - & 0 \\
\hline 25 & 13 & 74 & 211.6 & 8 & 59 & 201.0 & 35 \\
\hline 26 & 0 & - & - & 0 & - & - & 0 \\
\hline 27 & 0 & - & - & 0 & - & - & 0 \\
\hline 28 & 0 & - & - & 0 & - & - & 0 \\
\hline 29 & 0 & - & - & 0 & - & - & 0 \\
\hline 30 & 7 & 51 & 202.8 & 10 & 51 & 190.8 & 28 \\
\hline 31 & 19 & 44 & 147.6 & 16 & 45 & 260.3 & 58 \\
\hline 32 & 6 & 48 & 254.1 & 5 & 46 & 234.1 & 18 \\
\hline 33 & 0 & - & - & 1 & 69 & 227.6 & 1 \\
\hline 34 & 0 & - & - & 0 & - & - & 0 \\
\hline
\end{tabular}


Table IX. Experiment III. Nymphal growth during the first 30 days.

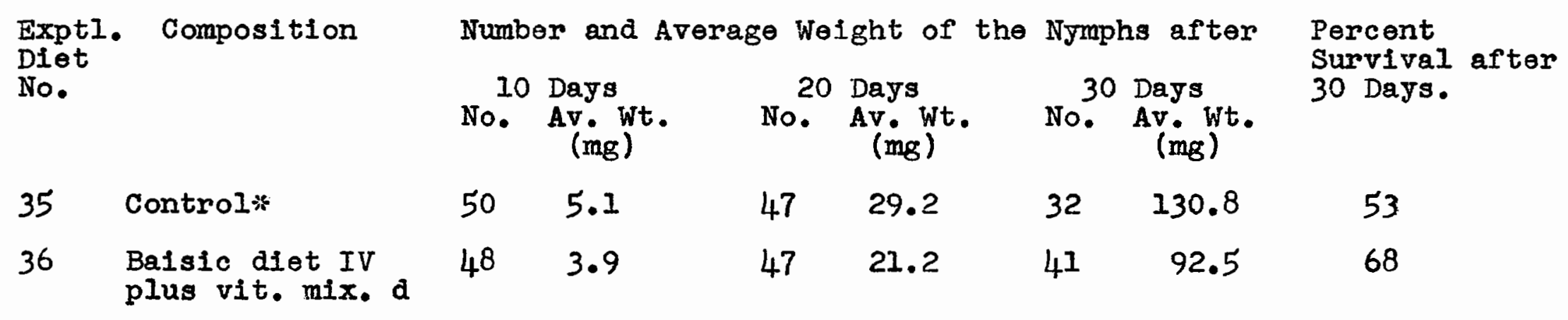

Table X. Experiment III. Average wolght of the adults, average duration of the nymphal stage, and percent survival.

\begin{tabular}{|c|c|c|c|c|c|c|c|}
\hline \multirow{2}{*}{$\begin{array}{l}\text { ExptI. } \\
\text { Diet } \\
\text { No. }\end{array}$} & \multicolumn{3}{|c|}{ Adult Males Obtained } & \multicolumn{3}{|c|}{ Adult Females Obtained } & \multirow[t]{2}{*}{ Percent Survival } \\
\hline & No. & $\begin{array}{l}\text { Av. Duration } \\
\text { of the Nymphal } \\
\text { Stage (days) }\end{array}$ & $\underset{(m g)}{A v t .}$ & No. & $\begin{array}{l}\text { Av. duration } \\
\text { of the Nymphal } \\
\text { Stage (days) }\end{array}$ & $\begin{array}{l}\text { Av. Wt. } \\
\text { (mg) }\end{array}$ & \\
\hline 35 & 9 & 40 & 214.6 & 10 & 36 & $261 \cdot 3$ & 31 \\
\hline 36 & 13 & 44 & 189.5 & 18 & 43 & 228.0 & 51 \\
\hline
\end{tabular}

